\title{
LA CONCEPCIÓN ARISTOTÉLICA DE LA SABIDURÍA EN SOBRE LA FILOSOFÍA
}

\author{
Claudia Seggiaro \\ UBA - CONICET \\ claudiasegg@gmail.com
}

\begin{abstract}
El objetivo de este trabajo es analizar la relación entre la concepción de la sabiduría y el uso de metáforas lumínicas presentes en los fragmentos $8 \mathrm{~b}$ y $8 \mathrm{c}$ de Sobre la filosofía. Al hacer esto, nos interesa establecer si el uso de esta metáfora responde a la utilización que Aristóteles hace de términos perceptuales en otras obras, como la Física, la Metafisica, Sobre el alma y el Protréptico. El objetivo de este análisis es examinar si, al hacer uso de la metáfora lumínica en estos fragmentos, Aristóteles supone la distinción entre "lo más más conocido en sí" y "lo más conocido para nosotros", presentada en las obras arriba mencionadas como "lo más claro en sí" y "lo más claro para nosotros", esto es, en términos perceptuales.
\end{abstract}

Sobre la filosofia / sophía / sapheía / primeros principios / conocimiento

\section{THE ARISTOTELIC CONCEPTION OF WISDOM IN ON PHILOSOPHY}

The aim of this paper is to analyze the relationship between wisdom and the use of luminic metaphors present in the fragments $8 \mathrm{~b}$ and $8 \mathrm{c}$ of On Philosophy. In this way, we want to establish whether the use of these metaphors responds to the uses that Aristotle do of perceptual terms in other works, such as the Physics, the Metaphysics, On the soul and the Protrepticus. The objective of this analysis is to examine whether, by making use of luminic metaphors in this fragments, Aristotle assumed the distinction between "better known in itself" and "better known to us", presented in the works mentioned as "clearer itself" and "clearer to us", that is, in perceptual terms.

On philosophy / sophía / sapheía / first principles / knowledge 
$\mathrm{E}$ n Sobre la filosofía la sabiduría es identificada con el conocimiento de los objetos más nobles y divinos. Si bien en los fragmentos conservados de esta obra Aristóteles no se detiene a analizar la naturaleza de esos objetos, su lectura a la luz del resto del corpus nos lleva a pensar que se trata de los principios inteligibles de las cosas. Estos son definidos como los objetos más luminosos, razón por la cual la sophía, en tanto es el conocimiento de esos principios, es equiparada con una especie de sapheía. La causa de esta metáfora lumínica puede encontrarse en que, si los primeros principios son los objetos más luminosos (fragmento $8 \mathrm{~b}$ ), ya que explican y fundamentan todas las demás cosas, la sabiduría, en tanto conocimiento de esos objetos, deberá ser aquella clase de ciencia que los ilumina y los vuelve cognoscibles.

Teniendo esto como telón de fondo, en el presente trabajo hemos elegido analizar la concepción aristotélica de la sabiduría basándonos en Sobre la filosofía, más específicamente en los fragmentos $8 \mathrm{~b}$ y $8 \mathrm{c}^{1}$, que nos han llegado a través de dos fuentes diferentes: Filópono y Asclepio. Nos interesa analizar particularmente los fragmentos 8b y 8c, ya que Filópono y Asclepio le atribuyen a Aristóteles un juego de palabras entre sophía y sapheía, cuyos antecedentes dentro del corpus aristotélico son escasos. Salvo en el segundo libro de la Metafisica (II 1, 993b 9-11) y en el fragmento 105 del Protréptico, el estagirita no realiza una analogía de este tipo.

No obstante, el uso del vocabulario perceptual para referirse al conocimiento no es completamente ajeno al corpus aristotélico. En este sentido, cabe destacar que en las obras conservadas, al referirse a "lo más conocido en sí" y "lo más conocido para nosotros", Aristóteles parece emplear expresiones tales como "más claro para nosotros" o "más claro en sí"2. Dado esto, en el presente trabajo queremos analizar cuál es el sentido de la relación entre la concepción de la sabiduría y esta metáfora presentada en los fragmentos mencionados (8b y 8c). A tal efecto, dividiremos el trabajo en dos secciones. En la primera abordaremos de forma esquemática el uso de términos perceptuales en algunas de las obras del corpus, como la Física, la Metafisica, Sobre el alma y el Protréptico. En la segunda parte, analizaremos los fragmentos $8 \mathrm{~b}$ y $8 \mathrm{c}$ de Sobre la filosofía. El objetivo de este análisis es examinar si, al hacer uso de la metáfora lumínica en estos fragmentos, Aristóteles supone la distinción entre "lo más más conocido en sí" y "lo más conocido para nosotros", presentada en las obras arriba mencionadas mediante términos perceptuales. Con esto pretendemos establecer si en Sobre la filosofía el uso de metáforas lumínicas puede atribuirse al propio Aristóteles.

Para la numeración de los fragmentos de Sobre la filosofía seguimos la edición de Ross.

2 Física I 1, 184a 16- 22, Tópicos I 17, 108a 18-25, Ética Eudemia I 6, 1216b 30-35. 
1. El uso de términos perceptuales para aludir al conocimiento en algunas obras del corpus aristotélico

Pese a que, como ya lo indicamos, el uso de la analogía entre el conocimiento de los primeros principios y la vista no es recurrente en los escritos aristotélicos a excepción del segundo libro de la Metafísica y el fragmento 105 del Protréptico, se debe destacar que hay en el corpus cierto uso de terminología perceptual para referirse a un tipo de conocimiento que no necesariamente tiene esa naturaleza. En este sentido, si bien en este trabajo no nos centraremos en la epistemología aristotélica en general, sino que nos interesa la concepción de la sabiduría en Sobre la filosofia, creemos relevante hacer una mención al respecto, ya que esto nos permitirá entender cómo Aristóteles emplea en su texto fragmentario ese vocabulario perceptual. Para ello, nos basaremos en algunos trabajos ya realizados sobre el tema que nos permita clarificar la cuestión en un texto menos trabajado como lo es Sobre la filosofía ${ }^{3}$.

Dividiremos este apartado en dos secciones: en la primera analizaremos el binomio "más claro para nosotros" y "más claro en sí o por naturaleza", como un modo de expresar las frases "más conocido para nosotros" y "más conocido en sí". En la segunda parte, examinaremos la contraposición entre la luminosidad de los principios y las dificultades que tiene el hombre para conocerlos presente en Metafisica II y en el fragmento 105 del Protréptico.

\section{A1- "Lo más claro para nosotros" y "lo más claro en sî"}

Una de las cuestiones metodológicas recurrentes en la obra aristotélica es la indagación sobre cómo podemos acceder al conocimiento independientemente del ámbito de estudio del que se trate. En este sentido, es clave la distinción que Aristóteles realiza entre lo que es "más cognoscible para nosotros" y "lo más cognoscible en sí". "Lo más cognoscible para nosotros" es aquello que cae bajo los sentidos o aquello con lo cual nos enfrentamos en el trato diario con las cosas ${ }^{4}$. Lo cognoscible en sí se identifica con lo más alejado de los sentidos ${ }^{5}$, con lo kathólou e inteligible, esto es, con aquello que es causa y principio de las otras cosas. Para Aristóteles, llegamos a tener verdadero conocimiento cuando hay una plena identificación entre ambas cosas y esto sucede cuando obtenemos el co-

3 Podemos mencionar a Cleary (1988), Dooler (1992), Lesher (2010), Lugarini (1972), Zanatta (2008).

4 Tópicos VI 4, 141b 10-11.

5 Tópicos VI, 141b 6-10. 
nocimiento de lo más cognoscible en sí ${ }^{6}$. Lo que nos interesa de esta distinción es que, en algunos contextos, para sistematizarla Aristóteles recurre al uso de expresiones perceptuales. En el primer libro de la Física, sostiene:

El procedimiento natural es partir de las cosas más cognoscibles y claras para nosotros y remontarnos a las más claras y cognoscibles por naturaleza. En efecto, no es lo mismo cognoscible para nosotros y "cognoscible en sentido absoluto". Precisamente por eso es forzoso proceder de este modo: partir de las cosas menos claras por naturaleza pero más claras para nosotros y remontarnos a las cosas más claras y cognoscibles por naturaleza (trad. Boeri) ${ }^{7}$.

En este pasaje, Aristóteles no distingue simplemente entre "lo más cognoscible en sí" y "lo más cognoscible para nosotros" ${ }^{8}$, sino también entre "lo más claro en sí" y "lo más claro para nosotros". Esta distinción está relacionada con el hecho de que para Aristóteles el conocimiento en sentido pleno presupone el descubrimiento de los principios. De las palabras del estagirita se puede inferir que sólo podemos dar cuenta de las cosas cuando conocemos sus principios, razón por la cual lo que realmente otorga claridad a las cosas es la adquisición de estos principios. Sin embargo, pese a ser lo más manifiesto en sí, debido a que estos no son de carácter sensible, para nosotros son lo más oscuro 9 . Lo que se desprende de este pasaje es que lo más claro y cognoscible recibe este calificativo desde la perspectiva desde la cual se lo enfoque. Los principios de las cosas son lo más claro porque son lo que permite tener conocimiento en sentido estric-

6 Tópicos VI 4, 142a 9- 12. Sin duda, lo más conocido sin más no es lo conocido para todos, sino para los que tienen bien dispuesto el pensamiento, así como, por ejemplo, lo saludable sin más lo es para los que tienen bien el cuerpo.

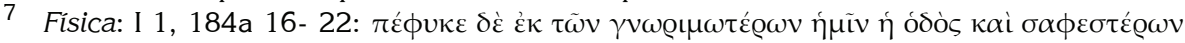

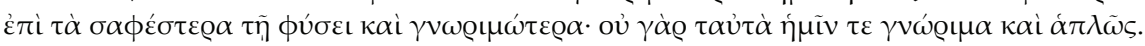

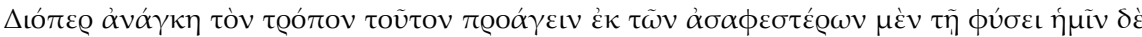

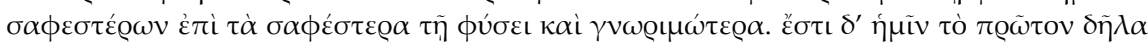
$\kappa \alpha \grave{i} \sigma \alpha \phi \tilde{\eta} \tau \dot{\alpha} \sigma v \gamma \kappa \varepsilon \chi v \mu \varepsilon \dot{v} \alpha \mu \tilde{\alpha} \lambda \lambda \mathrm{ov}$.

8 Metafisica VII 3, 1029a 1-4: "es, desde luego, provechoso avanzar hacia lo más cognoscible, ya que el aprendizaje se lleva a cabo, para todos, procediendo así: a través de las cosas menos cognoscibles por naturaleza hacia las cosas que son más cognoscibles en mayor grado".

9 Metafisica I2, 982a 21-23: "y sin duda, lo katólou en grado sumo es también lo más difícil de conocer para los hombres (pues se encuentra máximamente alejado de las sensaciones)". Alejandro de Afrodisia (Comentario a la Metafisica 12 5-15) considera que en este pasaje Aristóteles está retomando la distinción realizada en la Física entre "lo más conocido para nosotros" y "lo más conocido en sí". Por tal motivo, el comentador aclara que aquello que es descripto como katólou no recibe este calificativo en el mismo sentido en el cual lo reciben los géneros, sino en el sentido de que es primero respecto de las sensaciones.

ARgOS 39 (2016) ISSN 0325-4194, pp. 68-91 
to. Sin embargo, en función de su naturaleza, son lo más distante para nosotros, razón por la cual son lo más difícil de conocer y, por ende, lo más oscuro $^{10}$. Lo inverso sucede con lo sensible: la familiaridad que tenemos con lo sensible hace que sea lo más claro para nosotros, pero en función de que no da cuenta de lo que las cosas son, esto es, dado que encubre la verdadera naturaleza de las cosas, oscurece su conocimiento, siendo, por este motivo, lo menos claro y manifiesto en sí. Según Lesher ${ }^{11}$, al afirmar que debemos ir de "lo más conocido para nosotros" a "lo más conocido en sí", Aristóteles está planteando la existencia de un movimiento del alma hacia un discurso definitivo que comienza desde las cosas que son oscuras, pero más evidentes para nosotros, y progresa hacia lo que es claro o más conocido. En este sentido, coincidimos con Lugarini ${ }^{12}$ en cuanto a que la distinción ontológica entre lo más claro para nosotros y lo más claro en sí es el fundamento de la distinción gnoseológica entre lo más cognoscible para nosotros y lo más cognoscible en sí. Desde la perspectiva de este autor, que la cosa sea clara en sí misma es la precondición de su cognoscibilidad. El discernimiento de este tipo de cosas constituye conocimiento en sentido estricto, mientras que el de las cosas que son claras para nosotros constituye un conocimiento "pre- epistémico del saber mismo"13.

En Ética Eudemia encontramos una distinción parecida:

Todo hombre, pues, tiene algo propio en relación con la verdad, y partiendo de esto, debemos aportar alguna especie de prueba sobre estas materias. Partiendo, pues, de juicios verdaderos, pero obscuros, y

10 Lugarini (1972: 91) señala que existen diferentes grados de "claridad". El grado más elevado remite a lo que es constitutivamente claro, esto es, a aquello cuya manifestación constituye "una verdad". El segundo grado de claridad está relacionado con aquello que se manifiesta en la forma de "fenómeno". La distinción epistemológica entre "lo más cognoscible en sí" y "lo más cognoscible para nosotros" tiene sus raíces aquí. De hecho, dice Aristóteles que las cosas más claras y cognoscibles para nosotros son aquellas menos claras por naturaleza, y no al revés.

Se debe resaltar que es problemático establecer si todos los hombres cumplen o pueden cumplir con este proceso. Lo que resulta evidente es que potencialmente todos los hombres podrían hacerlo, pues tienen esa tendencia natural y las facultades para hacerlo. Ahora bien, que todos los hombres puedan hacerlo no quiere decir que todos los hombres actualicen su potencialidad de conocer, logrando alcanzar el conocimiento de lo manifiesto y claro en sí mismo.

11 Lesher (2010: 152).

12 Lugarini (1972: 91).

13 Lugarini (1972: 92). Para este autor, la separación moderna entre método y conocimiento está ausente en el pensamiento aristotélico. Ambas cuestiones están unidas: el método no es otra cosa sino el movimiento del saber. Desde la perspectiva de este autor, la búsqueda de los principios se mueve dentro de la cosa y se adentra de un grado de claridad a otro más originario, esto es, va de los fenómenos a la alétheia.

ARgos 39 (2016) ISSN 0325-4194, pp. 68-91 
avanzando, llegaremos a otros claros, si reemplazamos las afirmaciones confusas habituales por otras más conocidas (trad. Pallí Bonet) ${ }^{14}$.

Según Woods ${ }^{15}$, en el pasaje citado de la Ética Eudemia, al hablar de la poca claridad de las opiniones existentes, Aristóteles no solo estaba aludiendo a su oscuridad, sino también a su falta de certeza, esto es, a su inexactitud. Sobre esta base, este autor sostiene que, al tomar como punto de partida esas opiniones, Aristóteles estaría presuponiendo la distinción entre "lo más inteligible en sí" y "lo más inteligible para nosotros", que se puede rastrear en pasajes tales como Analíticos posteriores I 2, 71b 33ss, y el pasaje citado de la Física (I 1, 184a 16- 22). No obstante, al leer este pasaje de la Ética Eudemia a la luz de esta interpretación, se tiene que tener en cuenta que se trata de un tratado de naturaleza diferente a los arriba citados, pues versa sobre las ciencias prácticas. En el pasaje citado de la Ética Eudemia, al decir que todos los hombres participan en algo de la verdad, Aristóteles está aludiendo a sus opiniones sobre lo que es la vida feliz. Ahora bien, dichas opiniones, que son lo más conocido para estos hombres, no tienen su origen en la observación, sino en lo que usualmente se cree en torno a este tema. Dado esto, se podría afirmar que bajo la categoría "más inteligible para nosotros" Aristóteles no solo supone las opiniones que pueden surgir a partir de las impresiones sensibles sino también aquellas opiniones que por estar en el acervo cultural nos resultan lo más familiar.

Si se interpreta el pasaje de la Ética Eudemia desde esta perspectiva, partir de las opiniones existentes y, por lo tanto, ir de lo más oscuro a lo más claro implica tomar como punto de partida lo más cognoscible para nosotros. El procedimiento a seguir sería encontrar lo que hay de verdadero en estas opiniones y dar cuenta de ello para, luego, poder acceder a lo inteligible en sí, itinerario que vuelve a repetir el proceso descripto en el pasaje anteriormente comentado de la Física.

En el fragmento 102 del Protréptico, Aristóteles realiza una asociación análoga entre el conocimiento y lo más claro y honorable:

También el hecho de que la mayoría rehúya la muerte muestra el amor del alma por el saber, pues rehúye lo que no conoce, lo oscuro y lo que no es claro, mientras que por naturaleza persigue lo manifiesto y cognoscible. También decimos mayormente por esto que debemos honrar por encima de todo a quienes son causa de que veamos el sol y la luz

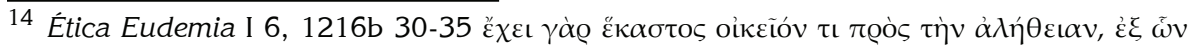

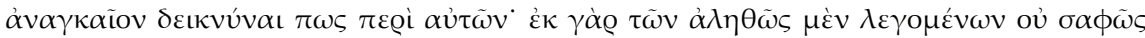

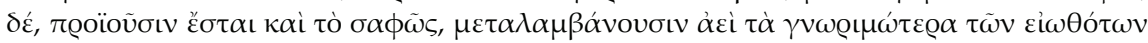
$\lambda \varepsilon ́ \gamma \varepsilon \sigma \theta \alpha \iota \sigma v \gamma \kappa \varepsilon \chi v \mu \varepsilon \dot{v} \nu \omega \varsigma$.

15 Woods (2005: 58). 
y que debemos venerar a nuestro padre y a nuestra madre como causa de nuestros mayores bienes. Son causa, según parece, de que podamos pensar y ver. Por este mismo motivo nos alegramos con todo aquello que nos resulta acostumbrado, ya sean cosas o personas, y llamamos queridos a los conocidos. Así pues, esto muestra claramente que lo cognoscible, lo manifiesto y lo evidente es deseable y, si lo son lo cognoscible y lo claro, evidentemente será por necesidad también el conocer y del mismo modo el pensar (trad. Vallejo Campos) ${ }^{16}$.

De este pasaje, nos interesa resaltar la tesis según la cual el miedo humano a la muerte se debe al temor a lo desconocido. Lo relevante de esta tesis es que, al proponerla, Aristóteles establece dos campos semánticos contrapuestos: el de lo conocido y el de lo desconocido. El primero es descripto con los epítetos de "oscuro" y "no claro"17; el segundo con el adjetivo "manifiesto". Lo más conocido es lo más manifiesto pues arroja luz sobre el resto de las cosas.

En relación con esta tesis, el otro punto relevante de este fragmento es el uso de "physei". El motivo por el cual nos interesa el empleo de este circunstancial es que, al igual que en la Física, Aristóteles señala que lo que está describiendo es un proceso que el hombre realiza naturalmente. Desde la perspectiva aristotélica, si lo cognoscible, lo manifiesto y claro es lo más deseable, entonces también deben serlo el conocer y pensar. Tal placer o deseo no sería uno más entre otros, sino constitutivo de la naturaleza humana.

Queda difuso en el fragmento 102 del Protréptico cuál es el referente de los adjetivos "claro" y "cognoscible". Tenemos cierta evidencia de que deben de ser las ousíai y causas descriptas en los fragmentos 33 y 35 o los objetos inteligibles mencionados en el fragmento 24. Si así fuera, el investigar y el conocer serían las actividades más deseadas, pues por ellas llegamos a poseer esos objetos o causas que son caracterizados como "lo que es más conocido" (gnostón) (Protréptico fragmento 33), "luminoso" (phanerón) y "claro" (dêlon) (Protréptico fragmento 102). Tal como lo indica

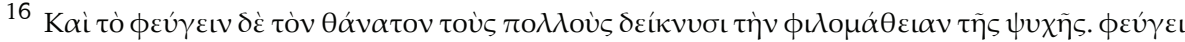

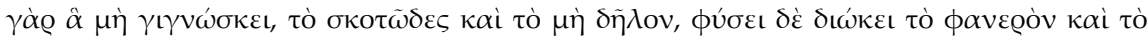

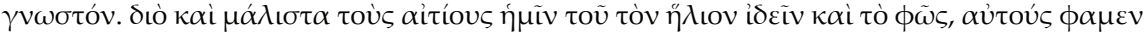

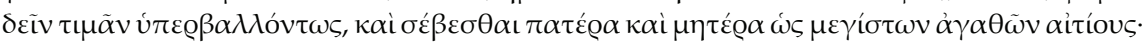

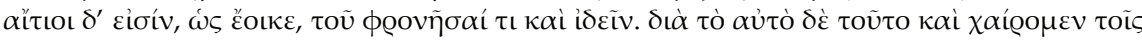

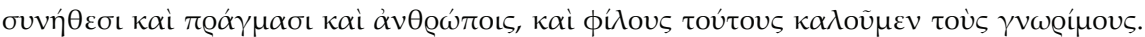

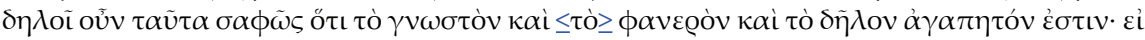

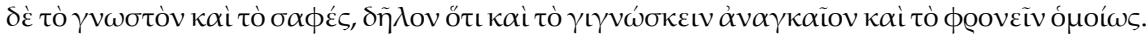

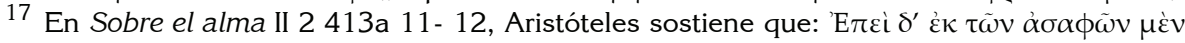

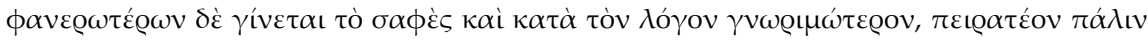

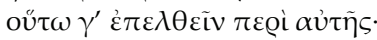


Zanatta ${ }^{18}$, el argumento del fragmento está estructurado sobre la relación entre sabiduría y claridad del conocimiento. Puesto que es el conocimiento de las causas o fundamentos ontológicos de todas las cosas (Protréptico fragmentos 33-35), la sabiduría será también aquel tipo de ciencia que los vuelve cognoscibles (Protréptico fragmentos 47-49). Por tal motivo, este tipo de conocimiento no solo es superior, sino también más claro, ya que es el conocimiento de lo que las cosas verdaderamente son. A través de él, es posible conocer el resto de las cosas; por lo tanto, si aceptamos la equiparación luz - conocimiento, presupuesta en el fragmento 102, las iluminará tornándolas visibles.

Si bien hemos adoptado la traducción de Vallejo Campos, según la cual el hombre "por naturaleza persigue lo manifiesto y cognoscible", también es posible traducir la frase del siguiente modo: "el hombre persigue lo que es manifiesto y cognoscible por naturaleza". Bajo esta lectura del texto, el hombre no busca cualquier tipo de conocimiento, sino que persigue aquello que por naturaleza es manifiesto y cognoscible. Esto cobra relevancia si tenemos en cuenta que una línea más arriba Aristóteles habría dicho que nos alegramos con aquello a "lo que estamos acostumbrados", esto es, habituados. La relación de ambos tipos de cosas, las conocidas por naturaleza y aquellas a las que estamos acostumbrados, refleja de alguna manera la conexión entre "lo más conocido para nosotros" y "lo más conocido en sí o por naturaleza". Los motivos que permiten dar cuenta de esta distinción aparecen en el primer capítulo del segundo libro de Metafisica, es decir, Alfa menor, y en el fragmento 105 del Protréptico que analizaremos a continuación.

A 2- Las comparaciones entre luz-conocimiento y entre oscuridaddificultad de conocer en Metafísica II y el fragmento 105 del Protréptico.

Los pasajes en los que Aristóteles expresamente usa analogías perceptuales se encuentran en el segundo libro de la Metafisica (II 1, 993b 9-11) y en el Protréptico (fragmento B 105). En ambas obras, Aristóteles enfatiza que la dificultad para conocer los primeros principios se encuentra en la naturaleza corpórea del hombre. Para dar cuenta de ello, se vale de la analogía con el murciélago en Metafísica II 1, 993b 9-11 y el parangón con Linceo en el fragmento 105 del Protréptico. Resulta llamativo que solo en estas dos obras Aristóteles use analogías de esta clase. La importancia de la utilización de estas analogías es que son del mismo tipo de las empleadas en los fragmentos $8 \mathrm{~b}$ y $8 \mathrm{c}$ de Sobre la filosofía. Se supone que, en la misma época en la que Aristóteles estaba trasmitiendo y escri-

18 Zanatta (2008: 268 n 64). 
biendo los contenidos de la primera versión de la Metafisica ${ }^{19}$, estaba redactando también este diálogo que se encuentra perdido. En la Metafisica, con el objetivo de fundamentar por qué la búsqueda de la sabiduría es en cierto sentido difícil, Aristóteles introduce el parangón con el murciélago:

como los ojos del murciélago respecto de la luz del día, así se comporta el entendimiento de nuestra alma respecto de las cosas que, por naturaleza, son las más evidentes de todas ${ }^{20}$.

En este pasaje, queda al descubierto que la dificultad para alcanzar la sabiduría no depende del objeto de estudio sino de la naturaleza del sujeto cognoscente. Es la imposibilidad de adaptar la vista lo que impide aprehender correctamente aquello que se quiere conocer. En este parangón, la luz del día representa el conocimiento de los primeros principios, que, en función de ser lo más conocido, son luminosos. Posiblemente por esto, Reale interprete que la luz del día es equivalente a la "evidencia absoluta" ${ }^{21}$. En el pasaje en cuestión, los ojos del murciélago son el equivalente al noûs humano, es decir, a aquella facultad por la cual se puede conocer los primeros principios. Según Alejandro de Afrodisia ${ }^{22}$, evidentemente el intelecto está unido a la sensación y a las potencias pasivas del alma, razón por la cual tiene algunos impedimentos para ejercer su actividad plenamente. Esta lectura parte del hecho de que el hombre no puede tener un conocimiento inmediato o intuitivo de los primeros principios, sino mediato, y de que dicho conocimiento debe comenzar por la percepción. Es-

${ }^{19}$ La relación entre Sobre la Filosofía y el segundo libro de la Metafisica está atravesada por una problemática: la autenticidad de este último libro. Alejandro de Afrodisia sostiene sin vacilar que Alfa menorfue escrito por Aristóteles. No obstante, debido al carácter inconcluso del texto y las sentencias finales, el comentador del estagirita es vacilante a la hora de establecer su lugar o función dentro de la Metafisica. Por momentos considera que es un escrito ubicado entre Alfa mayor y Beta (Comentario a la Metafisica 136, 4 y 18), pero en algunos pasajes de su comentario sostiene que habría sido una introducción a la Física o a la filosofía como un todo respecto de la cual la física es la primera parte (Comentario a la Metafisica 137, 1 y ss.).

Entre los intérpretes modernos, Berti (2005: 27-28) sostiene que Alfa menor era la introducción de la versión más antigua de la Metafisica. Desde la perspectiva de Szlezák, el libro que nos ha llegado como Alfa menor son fragmentos de alguna obra póstuma de Aristóteles escrita en diferentes momentos y que carece de unidad interna (la interpretación de Szlezák es tomada de Dooley (1992: 4)). Reale, por su parte, argumenta en favor de la unidad la Metafisica y sostiene que Alfa menor es un apéndice de Alfa mayor (1980: 39).

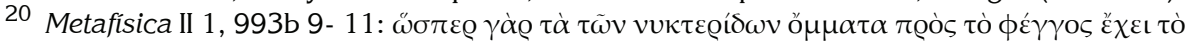

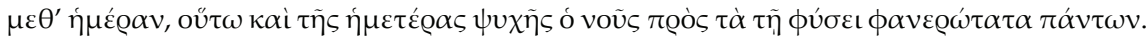

21 Reale (1997: 709).

22 Comentario a la Metafisica 142, 19-23. En el caso del comentario de Alejandro de Afrodisia seguimos la edición de Hayduck (1891).

ARgos 39 (2016) ISSN 0325-4194, pp. 68-91 
te análisis del pasaje de la Metafisica presupone la concepción epistemológica desarrollada en el tercer libro de Acerca del alma y prefigurada en algunos fragmentos del Protréptico, como por ejemplo el $24^{23}$. Según Aristóteles, el alma nunca intelige sin imágenes (Sobre el alma III 7, 431a 1617). De esto se desprende que para que el noûs pueda actualizarse y ejercer su función debe ser afectado por estas imágenes. Ahora bien, esto no significa que sea pasivo, pues, "el pensamiento es una actividad continua de manera que se puede decir que al mismo tiempo piensa y se piensa" 24 .

Sobre la base de lo argumentado, es evidente que en Metafisica II 1, 993b 9- 11 Aristóteles enfatiza que la ceguera, la poca adaptación a la luz o las tinieblas que impiden ver los objetos más honorables son ocasionadas por este modo particular que tiene el hombre de conocer que implica que el primer contacto con el objeto de conocimiento sea por los sentidos y, por lo tanto, esté mediado por el cuerpo. La imposibilidad de que el conocimiento de lo inteligible sea inmediato es la causa de que la adquisición de la filosofía sea una tarea difícil.

En el Protréptico, Aristóteles ofrece una explicación parecida basándose en una situación hipotética. Hacia el final del fragmento 105 trasmitido por Jámblico, el estagirita habría dicho:

Efectivamente, si alguien pudiera mirar con la agudeza atribuida a Linceo, que veía a través de muros y árboles, ¿̇podría haber considerado alguna vez a alguien digno de resistir la mirada, si hubiera visto las maldades de las que está compuesto? Los honores y la fama, que son más envidiados que ninguna otra cosa, están llenos de una futilidad indescriptible. Verdaderamente, para quien contempla una realidad eterna es necio esforzarse por todo esto. ¿Qué es grande o perdurable en las cosas humanas? Es, más bien, por nuestra debilidad y por la brevedad de la vida, creo yo, por lo que incluso esto nos parece importante (trad. Vallejo Campos) ${ }^{25}$.

23 Protréptico fragmento 24: "A su vez, son actividades del intelecto las intelecciones, que son visiones de objetos inteligibles de la misma manera que es actividad de la vista la visión de los objetos sensibles. Así pues, todas las cosas son deseables para los hombres con vistas a la intelección y el intelecto, puesto que las demás cosas son deseables con vistas al alma, pero el intelecto es lo mejor en el alma y todo lo demás está constituido para lo que es mejor".

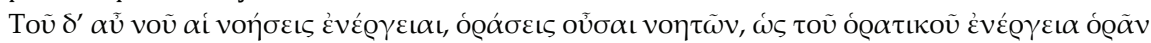

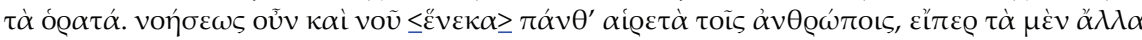

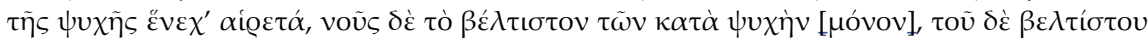

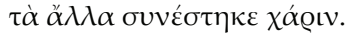

24 Berti (2004: 81). En relación con esto, véase la distinción trazada por Polansky (2007: 495) entre enérgeia y enteléchia.

25 En el fragmento 10 $\underline{a} 2$ trasmitido por Boecio en Consolación de la filosofía 3, 8, aparece la misma comparación: "Si, como dice Aristóteles, los hombres pudieran ver con los 
Una de las preguntas que podemos hacernos en torno a este fragmento es por qué Aristóteles realiza esta comparación con la vista de este personaje en particular y cuál es la función que dicha comparación juega en la economía del texto. En este sentido, es importante llamar la atención sobre el hecho de que Linceo era uno de los personajes de los argonautas cuya nota característica era su increíble agudeza para ver objetos a grandes distancias, incluso atravesando muros y cualquier otro obstáculo visual $^{26}$. De hecho, el nombre Linceo suele estar asociado con leússo, verbo arcaico utilizado solo en el lenguaje épico y cuyo significado es "dirigir la mirada hacia" o "ver".

Como es sabido el mitologema sobre el cual Andrónico de Rodas escribió Los argonautas aparece en la Iliada ${ }^{27}$, en la Odisea ${ }^{28}$ y es retomado por poetas épicos, entre los cuales se debe destacar Píndaro ${ }^{29}$ y Hesíodo ${ }^{30}$ y algunos otros autores, como por ejemplo Heródoto ${ }^{31}$. Esto significa que la historia junto con sus personajes estaba en el acervo cultural en el momento en que Aristóteles escribió su Protréptico ${ }^{32}$. En relación con el héroe mencionado, Vallejo Campos ${ }^{33}$ resalta que la comparación presentada en este fragmento había llegado a ser un tópico en la Antigüedad cuyos ecos pueden sentirse en el pasaje de la obra de Boecio que pretende ser una cita del Protréptico. El parangón en este sentido muestra la dificultad que el hombre tiene para conocer basándose en una situación hipotética pero irreal. Desde la perspectiva ofrecida por Aristóteles en este fragmento, si el hombre tuviera una visión que traspasase lo visible, tal como sucede con Linceo, no tendría dificultades en conocer aquello que es de naturaleza inteligible, pese a tener un cuerpo. Sin embargo, como tal situación no es real y tal visión es propia de un ser extraordinario y no humano, conocer lo que verdaderamente es es una tarea difícil que sólo puede comenzar por aquello que es más familiar para nosotros: lo sensible. No obstante, aquí se presenta el siguiente problema: los hombres en general no logran traspa-

ojos de Linceo, de manera que su mirada pudiera atravesar los objetos, cuando hubieran contemplado sus entrañas, ¿no parecería extremadamente feo aquel cuerpo de Alcibíades, que era bellísimo por fuera?" (trad. Vallejo Campos).

${ }^{26}$ La contrapartida de este fragmento es el fragmento 96, en donde Aristóteles termina diciendo: "en este mundo, tal vez por ser contraria a la naturaleza la condición del género humano, adquirir el saber e investigar son difíciles". (Fragmento 96, trad. Vallejo Campos).

27 Iliada VII 467-471, XXI 40-41 y XXIII 745-747.

28 Odisea XII 65-73.

29 Pitica IV 70-168.

30 Teogonía 965-1002

31 Historia IV 145 ss.

32 Para un a análisis de la trasmisión del mitologema de los argonautas, véase Valverde Sánchez (1996: 27).

33 Vallejo Campos (2005: 166). 
sar la frontera de lo sensible, razón por la cual toman lo que perciben por los sentidos como verdaderos bienes. Por este motivo, no buscan aquello que constituye su verdadero bien: los principios que determinan qué es verdaderamente bello, bueno y justo. Si bien en el Protréptico hay una dimensión ética ${ }^{34}$ que no aparece en la Metafisica, resulta evidente que en las dos obras Aristóteles plantea la naturaleza y limitación del conocimiento humano debido a que, si bien su objeto -los primeros principios- está en lo sensible, no es de naturaleza sensible, sino inteligible. Para dar cuenta de esta doble cuestión acude a una serie de analogías perceptuales y una terminología visual que aparecerán en las dos versiones del fragmento 8 de Sobre la filosofía, que analizaremos en el siguiente apartado.

\section{La concepción de sophía en los fragmentos $8 b$ y $8 c$ de Sobre la filosofía}

Los fragmentos $8 \mathrm{~b}$ y $8 \mathrm{c}$ suelen citarse para clarificar las palabras iniciales del segundo libro de la Metafísica. En ambos se pretende dar una definición de la sabiduría como el conocimiento de los objetos más luminosos. Lo que se desprende de la lectura de estas dos versiones de lo que habría sido un pasaje de Sobre la filosofía es que este conocimiento no puede ser de los objetos sensibles. La pregunta que surge es qué tipo de conocimiento está presentando Aristóteles en esta obra y qué pretende decir mediante el uso de metáforas lumínicas. Para responder estas dos preguntas, en este apartado nos abocaremos al análisis de estos dos fragmentos. En el fragmento 8 b Filópono ${ }^{35}$, citando a Aristóteles, dice:

Así pues, la sabiduría fue llamada así como si fuera cierta claridad, en tanto que clarifica todas las cosas. Esta condición de lo claro, al ser algo

34 Esto se debe a que las diferentes versiones que tenemos de este fragmento se refieren a valores éticos y no a principios ontológicos. De todos modos, se debe tener en cuenta que en el Protréptico Aristóteles aún no ha realizado la distinción entre plano teórico y práctico, con lo cual corresponde a la misma facultad conocer los principios ya sea ontológicos o éticos. Un claro ejemplo de esta falta de distinción son los fragmentos 46-50.

35 Según Westerink, al escribir el comentario sobre La introducción de la aritmética de Nicómaco y en él citar a Aristóteles, su intención no era interpretar la obra aristotélica, sino la de su maestro Amonio. No obstante, Westerink (1964: 535) resalta que para estudiar Sobre la filosofía se debe tener en cuenta esta obra, pues es la fuente más clara y precisa de la que disponemos.

Pese a esto la procedencia del comentario de Filópono no está exenta de dificultades. Algunos autores, como por ejemplo Tannery (1888), habían sostenido que la obra de Filópono estaba basada en un comentario perdido de Proclo. Contra esta filiación, Westerink (1964) y Tarán (1969) vinculan al texto con los cursos de Amonio. Tanto Tarán como Westerink tienden a considerar que el comentario de Filópono amplía y mejora la obra homónima de Asclepio, basada en las enseñanzas de su maestro Amonio.

ARgos 39 (2016) ISSN 0325-4194, pp. 68-91 
luminoso, recibe su denominación de la luz y la luminosidad, por traer a la luz las cosas que están ocultas ${ }^{36}$ (trad. Vallejo Campos) ${ }^{37}$.

El texto de Filópono pretende ser el comentario de la obra del pitagórico Nicómaco de Gerasa, contemporáneo de Numenio. Se tienen ciertas noticias de que los trabajos de Nicómaco circularon entre los neoplatónicos. La introducción de la aritmética estaba en los curricula de las escuelas neoplatónicas, siendo uno de los centros de las críticas de Proclo. En esta obra, Nicómaco considera que Pitágoras habría sido el primero en usar el término "sophía" con el sentido de "la ciencia del ser"38. Según Tarán9, a diferencia de Jámblico, cuyo objetivo era realizar un comentario a la obra de Nicómaco, el objetivo de Filópono, al escribir su comentario, era trazar la distinción ya existente en la escuela de Alejandría en los tiempos de Amonio entre theoría y léxis. La inserción de la cita de Aristóteles está vinculada con la intención de demostrar la tesis de que la sabiduría es el conocimiento de lo real y que lo real no es de naturaleza sensible, sino inteligible. En este contexto, Filópono cita a Aristóteles diciendo que en Sobre la filosofía (8b) el estagirita describe a la sabiduría como la ciencia de los objetos más luminosos. Para ello, le adjudica al estagirita un juego de palabras entre sophía (sabiduría) y sapheía (claridad), que en realidad está presente en buena parte del comentario. Nos interesa detenernos en primera instancia en esta asociación, respecto de la cual tuvimos ocasión de mostrar que no es extraña en los escritos del estagirita.

En relación con esto, es importante recalcar que en el léxico LiddellScott ${ }^{40}$ se señala que el término sapheía se habría acuñado para explicar el término sophía. Para dar cuenta de esto, se mencionan los pasajes correspondientes de Asclepio, en los cuales se estaría citando Sobre la

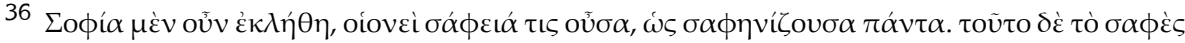

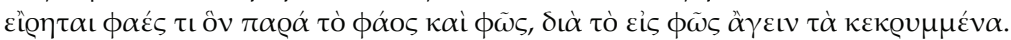
Para la cita de los pasajes de Filópono seguimos la edición de Bagel (1968).

37 La inclusión de este fragmento en las ediciones y traducciones de Sobre la filosofía ha sido motivo de algunas controversias. Jaeger (1991: 60 n. 28) lo cuestiona por su aparente impronta estoica. Bignone (1973: 519) lo considera parte del Protréptico de Aristóteles. Contra estas posturas, el paralelismo que se puede trazar entre este fragmento, Metafisica II y el fragmento 8c, que citaremos parcialmente más adelante, alentó a que autores como Festugière (1949: 587), Untersteiner (1960) y Berti (1997) lo consideren como perteneciente a una obra aristotélica y, dentro de estas a Sobre la filosofía.

38 O' Meara (1990:15). Desde la perspectiva de este autor, en esta obra Nicómaco habría identificado lo que es con las realidades inmateriales e inmutables, a las que contraponía con el mundo material cambiante. Para realizar esta distinción se habría valido del Timeo de Platón (27d).

39 Tarán (1969:16).

40 Liddell and Scott (1996: 1586). 
filosofía (el fragmento 8c). Otra acepción del término sapheía mencionada en el Liddell-Scott es el de conocimiento claro o lo que es claro o manifiesto a la mente. En el diccionario etimológico de Chantraine ${ }^{41}$, se aclara que la familia de palabras de este término expresa la idea de evidencia y de claridad, entendiendo por esto una visión objetiva. La relación entre este término y sophía nos permite suponer que la sabiduría es el desocultamiento de lo que verdaderamente es. Por tal motivo, no sólo es un indicador acerca de las características del saber más elevado, sino que, tal como lo veremos más adelante, nos da algunos indicios de cómo es el objeto de ese saber que en el pasaje citado de Filópono solo es nombrado mediante sus atributos.

En el caso de Sobre la filosofía, el vocabulario utilizado ha sido la causa de que muchos de los intérpretes hayan visto una influencia platónica en el texto. Tal es el caso de Berti, para quien ${ }^{42}$ "sobre la filosofía" significa "en torno a la ciencia de lo divino", que es una acepción típicamente platónica del concepto de la filosofía, en tanto es el conocimiento de la realidad suprasensible. Esta equiparación entre el conocimiento de lo que es primero en el orden ontológico, esto es, lo que es divino e imperecedero, con la sabiduría es, desde su perspectiva, un elemento platónico en la concepción aristotélica de sophía. Dicha vinculación entre las nociones platónica y aristotélica de sophía, así como el uso de términos relacionados con la percepción para dar cuenta de esta forma de saber, son las principales razones por las cuales Berti tiende a pensar que Aristóteles podría estar procediendo de una manera muy parecida a como lo hace Platón en algunos diálogos, como por ejemplo República, más específicamente, el libro VI, en el cual Platón ofrece el parangón entre la Idea de Bien y el sol ${ }^{43}$.

Si bien no analizaremos aquí el uso de las metáforas lumínicas en la obra platónica, es importante subrayar que hacia el final de República $\mathrm{VI}^{44}$, al introducir la Idea de Bien y querer hablar sobre su naturaleza, Platón plantea una problemática y abordaje muy parecidos a los presentados por Aristóteles en el fragmento 8b de Sobre la filosofía, en Metafisica (II 1, 993b 9-11) y en el fragmento 105 del Protréptico. Para Platón el bien es el principio más elevado, aquel por el cual todas las cosas tienen su ser y pueden ser conocidas. El Bien, al igual que los principios aristotélicos, en

41 Chantraine (1990: 991)

42 Berti (1997: 262).

43 Berti (1997: 266) sostiene que en Sobre la filosofia Aristóteles realiza una exposición pública de la confrontación de la doctrina de los principios enseñada por su maestro. Si bien en esta última obra Aristóteles sostiene la misma identificación realizada por Platón entre la sabiduría y el conocimiento de los principios inteligibles, ambos filósofos diferían acerca de cuáles eran estos principios y cuál era su naturaleza.

44 República 515e 1-516b 7. Véase también Fedón 99 d 4- 100a 3. 
tanto otorga inteligibilidad a las cosas, es lo más luminoso ${ }^{45}$. No obstante, el hombre se encuentra incapacitado para conocerlo directamente, pues su propia naturaleza corpórea le impone un límite. Para poder conocer dicho principio, los hombres deberán realizar un camino progresivo de carácter ascendente en el cual irán adaptando su estructura cognitiva al objeto que desean conocer. En este sentido, este pasaje y otros análogos que aparecen en el corpus platónico nos llevan a acordar con la tesis de Berti sobre la herencia platónica en Sobre la filosofía. No obstante, creemos que, al conectar sophía y sapheía en este último escrito, Aristóteles implícitamente está trayendo a colación la distinción entre los objetos "más cognoscibles para nosotros" y los objetos "más cognoscibles en sí", que, tal como apuntamos en la primera parte de este trabajo, Aristóteles asimila a la distinción "más claro para nosotros" y "más claro en sí". El examen conjunto del corpus platónico y del aristotélico nos lleva a pensar que la presencia de concepciones platónicas en el fragmento 8b de Sobre la filosofía puede deberse no solo al legado platónico en el pensamiento aristotélico, sino también a la pertenencia de ambos pensadores a una tradición filosófica que tiende a vincular el saber y el conocimiento con la luz. Un ejemplo de esto es, sin lugar a dudas, Parménides ${ }^{46}$.

En la segunda parte del fragmento 8b, Filópono parece confirmar la tesis aquí defendida, a saber, que la metáfora lumínica luz/oscuridad que aparece en Sobre la filosofía presupone la distinción "más cognoscible en sí" / "más cognoscible para nosotros".

ciertamente, dado que las cosas inteligibles y divinas, como dice Aristóteles, a pesar de ser clarísimas en virtud de su propia entidad, a

$\overline{45}$ Por tal motivo, hacia el final del libro VI y comienzos del libro VII de la República, Platón intenta explicar la naturaleza de la Idea del Bien por medio de la analogía con el sol. Con tal fin, sostiene que la Idea del Bien es, para el resto de las Ideas y las cosas, lo que el sol para las cosas sensibles: la causa de su ser y de su cognoscibilidad. (Véase República VI 509b)

46 En los fragmentos que conservamos de su poema, Parménides recurre al binomio luz y oscuridad para hablar del acceso a la verdad. Así, por ejemplo, en 28 B1, 8-11 (S.E, Adv. Math. VII 111) Parménides habría afirmado: "Cuando con prisa me condujeron las doncellas Helíades, tras abandonar la morada de la noche, hacia la luz, quitándose de la cabeza los velos con las manos. Allí están las puertas de los senderos de la Noche y de Día".

En 28 B 9, 1-4 (Simpl, Fís. 180, 9-12) se nos dice: "Pero puesto que todo es denominado luz y noche y, según las cualidades de éstas, se aplican a unas cosas tanto como otras, todo está lleno a la vez de luz y de noche oscura, ambas iguales, ya que nada se aparta de ninguno de los dos".

Este modo metafórico para referirse al conocimiento e ignorancia en términos de luz y noche u oscuridad aparece en Cicerón, más precisamente en Sobre la naturaleza de los dioses 6, II, 37, 95-96. 
nosotros nos parecen tenebrosas y confusas, por la niebla en la que el cuerpo nos envuelve, es natural que le diera el nombre de sabiduría a la ciencia que trae estas cosas a la luz para nosotros. (La introducción de la aritmética de Nicómaco I 1. trad. Vallejo Campos).

En este pasaje del fragmento 8b, Filópono le atribuye a Aristóteles el hecho de que las cosas inteligibles y divinas pueden ser consideradas según su propia identidad o desde el punto de vista humano. La contraposición katà tèn eautôn ousían y hemîn, es sumamente importante. Si tenemos en cuenta que para Aristóteles la ousía de cada cosa es su esencia ${ }^{47}$, al afirmar que consideradas según su entidad las cosas inteligibles son claras, lo que está diciendo Filópono es que, según Aristóteles, las cosas vistas desde esta perspectiva son consideradas desde su naturaleza y, por lo tanto, son calificadas como claras cuando se las piensa en sí mismas. De esto se puede concluir que la contraposición realizada en el fragmento $8 \mathrm{~b}$ es entre las cosas consideradas en "sí mismas" y las cosas consideradas "en relación con nosotros" 48 , lo cual podría ser una variante de las distinciones entre "lo que es más cognoscible en sí" y "lo que es más cognoscible para nosotros" o "lo más claro en sí y "lo más claro para nosotros". Si bien la contraposición no es explícitamente formulada, como sucede en Física I 1, 184a 16- 22 o Metafisica VII 3, 1029a 1-4, está claramente presente en el fragmento y es indispensable para comprender el sentido de lo que se quiere trasmitir.

Bajo la perspectiva aquí presentada, el fragmento $8 \mathrm{~b}$ puede ser visto tanto como una explicación del proceder metodológico presentado por Aristóteles en Fisica I 1, 184a 16-22, Metafisica VII 3, 1029a 1-4, Ética Eudemia I 6, 1216b 30-35 y el Protréptico fragmento 102, como de la analogía usada en Metafísica II y en el fragmento 10a2 del Protréptico. Por un lado, Aristóteles reconoce que existen ciertos objetos que son en sí luminosos porque hacen cognoscible al resto de las cosas. Pero, por otro, admite que, dada nuestra naturaleza corpórea, esos objetos son para nosotros oscuros. Al igual que en la Física ${ }^{49}$ y la Ética Eudemia ${ }^{50}$, Aristóteles estaría

47 Metafisica VII 7, 1041b 4-9; 1041b 28-31.

48 En su comentario a los Analíticos posteriores I 33, 89a 38, pp. 8-22, Filópono presupone la misma distinción al sostener que, según Aristóteles, cierto conocimiento es llamado "sabiduría como si la sabiduría fuese algo a partir de lo cual las cosas divinas llegasen a ser más claras para nosotros: pues las cosas divinas son, como Aristóteles mismo lo dice, las cosas más manifiestas (phanótata) y también las más claras. <Son > más manifiestas por su propia naturaleza (dià tèn heautôn phýsin), pero <son> las más claras puesto que el conocimiento (gnôsis) se produce para nosotros a partir de las cosas más visibles". (trad. propia. Edición de Wallies (1909))

49 Fisica I 1, 184a 16-22 (citado en la primera parte del presente trabajo).

50 Ética Eudemia I 6, 1216b 30-35 (citado en la primera parte del presente trabajo). 
analizando la misma clase de objetos desde dos perspectivas diferentes: considerados en sí mismos y tomados desde el punto de vista humano. De acuerdo con cuál de estas dos perspectivas se tome, estos mismos objetos, los cuales presuponemos que son los primeros principios y causas, resultan claros u oscuros.

En nuestra lectura presuponemos que "lo más conocido en sí" en Sobre la filosofía deben ser los primeros principios y causas, pues, si bien en los pasajes aquí analizados no se los llama así, en otras obras aristotélicas contemporáneas a Sobre la filosofía, como por ejemplo en el Protréptico -fragmentos 33-36-51, Aristóteles dice que los objetos más cognoscibles son las causas y principios supremos. Esta misma tesis aparece en la Metafisica, en donde Aristóteles sostiene que "cognoscibles en grado sumo son los primeros principios y las causas (pues por estos y a partir de estos se conoce lo demás, pero no ellos por medio de lo que está debajo < de ellos >) (Metafisica I 1, 982b 2-4 trad. Calvo Martínez) ${ }^{52}$.

Una versión en cierto sentido paralela del pasaje citado del fragmento $8 \mathrm{~b}$ nos ha llegado a través del comentario de Asclepio a la Metafisica ${ }^{53}$ :

"Hay que tener en cuenta que se titula Sabiduría, Filosofía, Filosofía Primera y Metafísica, puesto que habiendo tratado sobre cuestiones físicas anteriormente, en esta obra trata de entidades divinas; en consecuencia, a causa de este orden, recibió tal denominación: se llama sabiduría (sophía). Como si fuera una cierta claridad, pues las entidades divinas son claras y manifiestas en grado máximo y esta ciencia trata, efectivamente, de entidades divinas. En atención a ello la llama 'Sabiduría'. De hecho, en la Apodíctica afirma: "como ya lo he dicho, en los tratados Sobre la Sabiduría”" (trad. Vallejo Campos) ${ }^{54}$.

51 Paralelamente en Tópicos I 2, 101 b, Aristóteles define los principios como lo primero respecto de todas las cosas.

52 En Metafisica V, 1013a 17-20 se refiere a estos mismos principios diciendo que "lo común a todo tipo de principios es ser lo primero a partir de lo cual algo es, se produce o se conoce" (trad. Calvo Martínez).

53 Es importante señalar que Amonio y Asclepio habían realizado un análisis minucioso de los primeros siete libros de la Metafisica de Aristóteles, incluido el libro Alfa Menor. Según Cardullo (2008: 244-245), el comentario de Asclepio a Alfa es el único comentario de inspiración neoplatónica en lengua griega, redactado de "la voz" de Amonio. Como consecuencia de esto y en función de que Amonio era maestro de la escuela neoplatónica de Alejandría, la obra de Asclepio, sobre todo el comentario de Alfa Menor, habría dado cuenta de una línea de pensamiento pre-plotiniana que abrigaba en su seno algunos dogmas cristianos. Para la distinción entre la escuela neoplatónica de Atenas y Alejandría, véase Cardullo (2008).

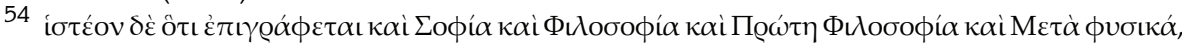

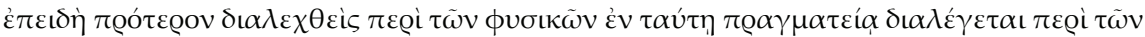

ARgos 39 (2016) ISSN 0325-4194, pp. 68-91 
Es importante notar que el pasaje del comentario de Asclepio no es incluido como un fragmento de Sobre la filosofía por todos los editores o traductores del texto. Los editores que lo incluyen son Untersteiner y Giannantoni. No es tenido en cuenta por Ross, cuya edición es seguida por gran parte de los traductores del texto, ni por Cherniss ${ }^{55}$, quien considera que Asclepio estaría aludiendo al pasaje de Metafisica II 1, en el cual Aristóteles presenta la analogía entre los ojos del murciélago y el noûs (II 1, 993 b7-11).

Desde nuestra perspectiva, aun cuando Cherniss estuviese en lo cierto, la continuidad argumentativa que se puede rastrear entre Metafisica y Sobre la filosofía hace que la interpretación de Asclepio siga siendo pertinente para el estudio de esta última obra. En este sentido cabe destacar que el pasaje correspondiente a la obra de Asclepio comienza como el comentario de Filópono: identificando la sabiduría con el conocimiento de los objetos más luminosos y divinos. Esto nos permite afirmar que, más allá de que Asclepio esté comentando un pasaje de Metafisica II, la presencia de esta cuestión en Sobre la filosofía hace que las palabras del comentador de Aristóteles sean importantes para dilucidar la noción de sophía presente en esta última obra.

Al comentar las primeras líneas de la Metafisica, Asclepio presenta la concepción aristotélica de sophía como una especie de luz, pues se ocupa de las entidades divinas y más claras. Como lo habíamos subrayado en relación con el fragmento 102 del Protréptico, la característica de ser una luz le adviene a la sabiduría de su objeto de estudio. Pero, ¿cómo entender la caracterización de las entidades divinas como las más claras ${ }^{56}$ ? Por los pasajes analizados de la Física, de la Metafisica y de la Ética Nicomáquea sabemos que "lo más claro" puede significar "lo más conocido en sí mismo" y que una de las posibilidades es que "lo más conocido en sí mismo" sea lo que es anterior por naturaleza ${ }^{57}$. Es decir, en la expresión "más claro" no solo entra en juego la prioridad gnoseológica sino también la ontológica. En su influyente libro sobre la prioridad en Aristóteles, Cleary subraya

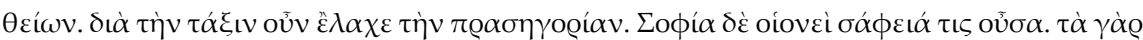

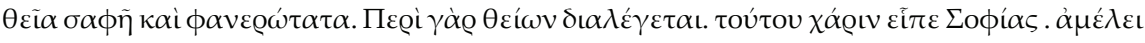

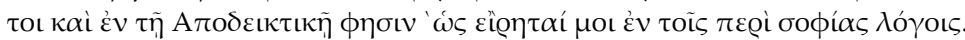

55 Cherniss (1959:38).

56 La noción de claridad está emparentada con la noción de anterioridad ontológica y epistemológica. Para el análisis de la noción de anterioridad en Aristóteles, véase Cleary (1988).

57 Categorías 13, 14b 11-13: "en efecto, entre las cosas reversibles según la implicación de existencia podría verosímilmente decirse que la causa de la existencia de cualquier otra cosa es anterior por naturaleza".

Metafisica V 1019a 1-3 "Algunas cosas se dice que son anteriores y posteriores en este sentido, y otras que lo son según la naturaleza y la entidad: así, todas las cosas que pueden existir sin otras, pero no estas sin ellas, distinción esta que utilizaba Platón".

ARgOS 39 (2016) ISSN 0325-4194, pp. 68-91 
que se debe partir del supuesto de que el orden del conocimiento sigue el orden del $\operatorname{ser}^{58}$. Bajo este supuesto, los entidades divinas son anteriores porque, además de ser el fundamento ontológico de las cosas, son las causas por las cuales estas pueden ser conocidas. La metáfora lumínica sirve para resaltar esta doble prioridad de las entidades divinas sobre el resto de las cosas, pues son anteriores por naturaleza y son aquello que es más conocido en sí mismo. La sabiduría, al ser el conocimiento de esas entidades, pasa a ser definida también como una luz que destierra la tiniebla de la ignorancia haciendo que realicemos el pasaje de lo más conocido para nosotros a lo más conocido en sí.

Otro pasaje en el cual Asclepio reproduce la misma metáfora lumínica forma parte del comentario a la Introducción de la aritmética de Nicómaco ( $\alpha$ 9-12):

Aristóteles llama más luminosas a las cosas que se manifiestan a sí mismas y <son> puras, pues verdaderamente la claridad a través de sí misma lleva de este modo a las cosas cubiertas en las penumbras de la ignorancia hacia la luz y el conocimiento ${ }^{59}$.

Este pasaje no es citado en relación con Sobre la filosofía. Sin embargo, teniendo en cuenta que en él Asclepio cita directamente a Aristóteles y que la obra homónima de Filópono arriba citada estaría basada en esta, su análisis es, al menos, pertinente.

En este pasaje, Asclepio adjudica a Aristóteles la misma relación entre sophía y los objetos más luminosos que aparece en $8 \mathrm{~b}$ de Sobre la filosofía y en su comentario a la Metafisica. El uso del lenguaje cognitivo y perceptual nos permite decir que la caracterización de los objetos más luminosos que Asclepio le adjudica a Aristóteles resulta ser paralela a la descripción de las cosas más conocidas realizada en el fragmento 102 del Protréptico. Por tal motivo, se puede inferir que en ambos tratados, ya sea en el comentario de Asclepio como en la obra perdida de Aristóteles, se está hablando de las mismas entidades o principios. En el pasaje citado, Asclepio enfatiza la distinción entre lo que es más cognoscible y lo menos cognoscible apelando a las metáforas de claridad y oscuridad. Se debe destacar en es-

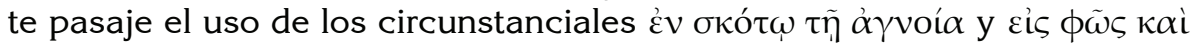
$\gamma v \tilde{\omega} \sigma \iota v$. La claridad o verdad, ambas traducciones posibles para saphés, es lo que saca a las cosas de la niebla de la ignorancia y las lleva hacia la luz o el conocimiento. Podemos ver nuevamente el juego de palabras entre

58 Cleary (1988: 45)

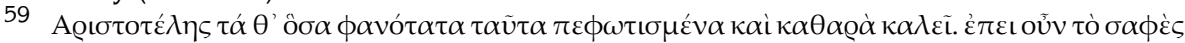

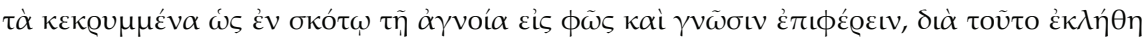

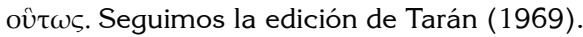


sophía, sapheía y conocimiento. Al igual que en el fragmento 102 del Protréptico, en este pasaje Asclepio reproduce la distinción entre dos campos semánticos, el constituido por las cosas claras y el conformado por las cosas oscuras. Por tal motivo, podemos decir que, al igual que en esta última obra, Asclepio adjudica a Aristóteles el hecho de que la sabiduría debe ser aquello buscado como un verdadero bien, ya que, al ser el conocimiento de los objetos más luminosos, solo por medio de ella el hombre logra salir de la tiniebla en la cual la ignorancia lo envuelve ${ }^{60}$.

Esta asociación entre claridad y tiniebla pone en evidencia que el objeto de la sabiduría no puede ser un tipo de conocimiento que se obtiene por medio de los sentidos, ya que estos últimos, lejos de dejarnos ver con claridad, constituyen una traba para el verdadero conocimiento. De este modo, Aristóteles pretende establecer que lo que constituye el fundamento de lo captable por medio de los sentidos no puede ser hallado por los sentidos mismos, sino apartándose de ellos ${ }^{61}$. Esto no implica que el conocimiento pueda prescindir de lo sensible, sino que, tal como lo había dicho Aristóteles en el pasaje citado de la Física (I 1, 184a 16-22) es natural que en el conocimiento vayamos de lo más conocido para nosotros a lo más conocido en sí. La metáfora lumínica utilizada por Filópono y Asclepio traducen este proceso descripto por Aristóteles en muchas de sus obras y que constituye uno de los núcleos de su epistemología.

\section{Conclusiones}

En el presente trabajo hemos analizado la noción de sabiduría defendida por Aristóteles en Sobre la filosofía. Para ello, nos hemos abocado al análisis de los fragmentos $8 \mathrm{~b}$ y $8 \mathrm{c}$ trasmitidos por Filópono y Asclepio, respectivamente. En ambos fragmentos se sostiene que la sabiduría es concebida como una especie de conocimiento de los objetos que, en función de ser los principios ontológicos y epistemológicos de lo real, permiten arrojar luz sobre el resto de las cosas. Por tal motivo, en ambos fragmentos se equipara a sophía con una especie de sapheía o luz de los objetos más honorables o divinos. Nuestra hipótesis en relación con esto último es que, al describir la sabiduría, Aristóteles tiene en mente la distinción "más cognoscible en sí" y "más cognoscible para nosotros" que es descripta en alguno de los textos que conformar el corpus como "lo más claro en

60 Cabe destacar que la interpretación de Asclepio supone la misma dependencia entre el plano ontológico y el plano gnoseológico vista en el Protréptico y el fragmento $8 \mathrm{~b}$ de Sobre la filosofía. Debido a que los objetos más luminosos son el fundamento ontológico y gnoseológico del resto de las cosas, su conocimiento, esto es la sabiduría, puede ser caracterizado como una especie de luz.

61 Fragmento 76 del Protréptico, fragmento 8b de Sobre la filosofía. 
sí" y "lo más claro para nosotros". Por tal motivo, en el primer apartado del presente trabajo nos hemos detenido en el análisis de esta distinción, que, si bien no está formulada explícitamente en Sobre la filosofía, parece presupuesta. Allí establecimos que lo más claro o lo más oscuro recibe ese calificativo dependiendo de la perspectiva desde la cual se lo analice. Considerados en sí mismos los primeros principios son lo más claro, porque solo hay verdadero conocimiento cuando se conocen dichos principios. Sin embargo, debido a la naturaleza de estos principios, esto es, que son inteligibles, son lo más alejado de nosotros y, por lo tanto, lo más difícil de conocer. Para dar cuenta de la dificultad, nos hemos detenido en el examen de Metafisica II 1, 993 9-11 y el fragmento B 105 del Protréptico, en donde Aristóteles utiliza el parangón entre la vista del murciélago y la actividad noética y realiza la comparación entre la actividad cognitiva humana y la vista de Linceo, respectivamente. El análisis de estos extractos de la obra del estagirita a la luz de los fragmentos $8 \mathrm{~b}$ y $8 \mathrm{c}$ de Sobre la filosofía nos permite aseverar que la sabiduría es una clase de conocimiento que implica un proceso que va de "lo más conocido para nosotros" a "lo más conocido en sí". En este contexto, podemos decir que, como su objeto es aquello que es más conocido en sí mismo, es decir, lo más claro, la sabiduría constituye una especie de luz que ilumina el resto de las cosas. En este sentido, si bien el uso de las metáforas lumínicas para referirse a la sabiduría tiene un resabio platónico que nos remite a diálogos como el Fedón o la República, responde a concepciones que son aristotélicas. El propio Aristóteles en las obras que conforman el corpus se refiere al conocimiento en términos de claridad o como lo más claro. Prueba de esto son los pasajes analizados de la Física, la Metafisica, el Protréptico y la Ética Eudemia. Lo que se puede concluir sobre la base de lo analizado es que, en Sobre la filosofía, la sabiduría es definida como el conocimiento más elevado, el descubrimiento de los primeros principios o de los objetos inteligibles. En tanto estos principios son el fundamento ontológico de las cosas (Sobre la filosofía fragmento 16, Protréptico 33), son también los que permiten conocerlas. Conocer en sentido pleno implica alcanzar este saber que es respecto a los otros saberes superior y rector (Metafisica I 2 , 982a 4-18) y, por lo tanto, iluminador. 


\section{Bibliografía}

Ediciones y traducciones

Berti. E.- Rossitto. C. (2002) [1973], Aristotele, Il libro primo della Metafisica, introduzione, traduzione e commento di E.B. e C.R, Milano, Biblioteca Universitaria Rizzoli.

Boeri, M. (1993), Aristóteles, Física, libros I y II, introducción, traducción y notas de M.B., Buenos Aires, Biblos.

Boeri, M. (2010), Aristóteles, Acerca del alma, introducción, traducción y notas de M.B., Buenos Aires, Colihue.

Calvo Martínez, T. (2007), Aristóteles, Metafísica, introducción, traducción y notas de T.C.M., Madrid, Gredos.

Hayduck, M. (1891), Alexandri Aphrodisiensis in Aristotelis Metaphysica commentaria, Berlín, Reimer.

Hayduck, M. (1888) Asclepiin Aristotelis Metaphysicorum Libros A-Z Commentaria, Berlín, Reimer.

Hoche, R. (1867) Philoponus Commentary on Nicomachus' Introduction to Arithmetic, Berlin, Calvary.

Pallí Bonet, J. (1988), Aristóteles, Ética Nicomáquea - Ética Eudemia, introducción, traducción y notas de J.P.B., Madrid, Gredos.

Rose, V. (1966) [1886], Aristotelis qui ferebantur Librorum Fragmenta, Stuttgart, Teubner.

TARÁn, L. (1969), "Asclepius of Tralles: Commentary to Nicomachus' Introduction to Arithmetic", American Philosophical Society, New Series, Vol. 59, No. 4 (1969), pp. 1-89.

Ross, W. D. (1964), Aristotelis Dialogorum Fragmenta, Oxford, Clarendon Press.

Untersteiner, M. (1960), "I1 Peri philosophías di Aristotele", Rivista di filologia e d'istruzione classica, Vol. 8, pp. 337-362.

VAlLEJo CAMPOS, A. (2005), Aristóteles, Fragmentos, introducción, traducción y notas de A.V.C, Madrid, Gredos.

Wood, M. (2005) [1982], Aristotle, Eudemian Ethic. Book I, II, VIII, translated with commentary by M.W., New York, Clarendon Press Oxford.

Zanatta, M. (2008), Aristotele, I Dialoghi, introduzione, traduzione e commento di M.Z., Milano, Biblioteca Universitaria Rizzoli.

Zanatta, M. (2009), Aristotele, Metafisica, introduzione, traduzione e commento di M.Z., Milano, Biblioteca Universitaria Rizzoli. 
Bibliografía secundaria

Berti, E. (1997) [1962], La filosofia del "primo" Aristotele, Milano, Centro di Ricerche di Metafisica dell' Università Cattolica del Sacro Cuore.

BERTI, E. (2004) [1977], Aristotele: dalla dialettica alla filosofia prima, Milano, Bompiani.

Berti, E. (2004), Nuovi studi aristotelici, Brescia, Morcelliana.

Bignone, E. (1973), L'Aristotele perduto e la formazione filosofica de Epicuro, Firenze, La Nuova Italia, 2 vol.

Cardullo, R. L. (2009), "Una lettura neoplatonica di Metaphysica alpha: gli scolii di Asclepio di Tralle trascritti "dalla voce" di Ammonio", en Cardullo, R. L. (ed), Il libro Alpha della Metafisica di Aristotele tra storiografia e teoria, Atti del Convegno Nazionale, Catania, CUECM.

Chantraine, P. (1990) [1968-1980], Dictionnaire étymologique de la langue grecque. Histoire des mots, Paris, Éditons Klincksieck.

Cherniss. H. (1959), "Review of Saffrey", Gnomon 31, pp. 36-51.

Cleary, J. J. (1988), Aristotle on the Many Senses of Priority, The Journal of the History of Philosophy. Monograph Series, Carbondale, Illinois Univeristy Press

Dooler S. J. (1992), "Introduction" en Dooler S. J - Madigan A., Alexander of Afrodisias, On Aristotle's Metaphysics, New York, Cornell University Press.

LefeBvRE, R. (1997), "Faut-il traduire le vocable aristotélicien de 'phantasia' par 'représentation'?”, Revue Philosophique de Louvain, Quatrième SÉrIE, TOME 95, 4, pp. 587-616.

Festugiere, A. J. (1949) La Révélation d'Hermes Trismégiste avec un appendice sur l'Hermétisme arabe; par Louis Massignon, Paris, Galbadan.

Frede, M. (2001), "Metaphysics 1", en Frede, M., Charles, D, (ed.) Aristotle's Metaphysics Book Lambda: Symposium Aristotelicum, New York, Clarendon Press, pp. 54-80.

JAEGER, W. (1993) [1923], Aristóteles. Bases para la historia de su desarrollo, trad. cast. de J. Xirau y W. Roces, México, Fondo de Cultura Económica.

Lang, H. (1993), "The Structure and Subject of Metaphysics" Phronesis, 28, 1993, pp. 257-280

LIDDELL, H. and SCOTT, R. (1983) [1843], A Greek-English Lexicon, compiled by H.L. and R.S., revised and augmented throughout by H. S. Jones, Oxford, The Clarendon Press.

LugArINI, L., (1972), Aristotele e l'idea della filosofia (II edizione riveduta) Firenze, La Nuova Italia Editrice.

O'meara, D.J. (1990), Pythagoras Revived, Mathematics and Philosophy in Late Antiquit, New York, Clarendon. 
SafrRey (1955) Le Peri Philosophias d'Aristote et la théorie platonicienne des Idées nombres, Leiden, E. J. Brill.

Lesher J. H. (2010), "Saphêneia in Aristotle: 'Clarity', 'Precision', and 'Knowledge", APEIRON, pp. 143-156.

Polansky, R. (2007), Aristotle's De anima, New York, Cambridge University Press.

TANNERY, P. (1888), "Rapport sur une mission en Italie du 24 janvier au 24 février 18 86: Les commentairessur Nicomaque", en Archives des missions, 3e s., t. XIV, pp. 433-439.

Valverde Sanchez, M. (1996), Apolonio de Rodas, Argonáuticas, introducción, traducción y notas de M.V.S., Madrid, Gredos.

Wallies M. (1909) Philoponus Commentary on Aristotle's 'Posterior Analytics, Berlin, Reimer.

Westerink L. G. (1964), "Deux commentaires sur Nicomaque: Asclépius et Jean Philopon", Revue des Études Grecques, tome 77, fascicule 366-368, Juillet-décembre, pp. 526-535. 